Article

\title{
Belowground Competition Directs Spatial Patterns of Seedling Growth in Boreal Pine Forests in Fennoscandia
}

\author{
E. Petter Axelsson ${ }^{1}{ }^{*}$, Tomas Lundmark ${ }^{1}$, Peter Högberg ${ }^{1}$ and Annika Nordin ${ }^{2}$ \\ 1 Department of Forest Ecology and Management, Swedish University of Agricultural Sciences, \\ 90183 Umeå, Sweden; E-Mails: tomas.lundmark@slu.se (T.L.); peter.hogberg@slu.se (P.H.) \\ 2 Department of Forest Genetics and Plant Physiology, Umeå Plant Science Centre, Swedish \\ University of Agricultural Sciences, 90183 Umeå, Sweden; E-Mail: annika.nordin@slu.se \\ * Author to whom correspondence should be addressed; E-Mail: petter.axelsson@slu.se; \\ Tel.: +46-90-7868361; Fax: +46-90-7868414.
}

Received: 25 April 2014; in revised form: 11 August 2014 / Accepted: 21 August 2014 /

Published: 2 September 2014

\begin{abstract}
Aboveground competition is often argued to be the main process determining patterns of natural forest regeneration. However, the theory of multiple resource limitation suggests that seedling performance also depends on belowground competition and, thus, that their relative influence is of fundamental importance. Two approaches were used to address the relative importance of above- and below-ground competition on regeneration in a nutrient-poor pine (Pinus sylvestris) boreal forest. Firstly, seedling establishment beneath trees stem-girdled 12 years ago show that a substantial proportion of the seedlings were established within two years after girdling, which corresponds to a time when nutrient uptake by tree roots was severely reduced without disrupting water transport to the tree canopy, which consequently was maintained. The establishment during these two years also corresponds to abundances high enough for normal stand replacement. Secondly, surveys of regeneration within forest gaps showed that surrounding forests depressed seedlings, so that satisfactory growth occurred only more than $5 \mathrm{~m}$ from forest edges and that higher solar radiation in south facing edges was not enough to mediate these effects. We conclude that disruption of belowground competitive interactions mediates regeneration and, thus, that belowground competition has a strong limiting influence on seedling establishment in these forests.
\end{abstract}


Keywords: boreal forest; forest edge; pine regeneration; asymmetric competition; tree girdling

\section{Introduction}

Competition between plants for light, water and nutrients is one of the most powerful biotic interactions in nature and, as such, influences individuals, populations [1], communities [2] and, hence, ecosystem dynamics and evolution [3]. Competition may be a strong determinant of patterns of natural regeneration in plant communities; e.g., the natural or man-made removal of dominant individuals may release seedlings from competitive stress [4,5]. The intricacies underlying the basic mechanisms and ecological consequences of competition is thus of key importance in the management of various socioeconomically important ecosystems. For example, the development of forest management practices, including an uninterrupted maintenance of forest cover (i.e., continuous cover forestry) requires seedlings to establish under a semi-closed canopy and, so, in competition with dominant trees.

The relative effects of above- and below-ground competition may have an important influence on seedling recruitment under canopy trees [6,7]. The theory of multiple resource limitation predicts that seedling performance will depend on the availability of water and nutrients, as well as on the shading properties of the canopy formed by the overstory [8]. Theories of asymmetric competition suggest that understory plants (such as seedlings establishing beneath closed canopies) may be particularly sensitive towards competition for light, as this resource can be pre-emptied by dominant vegetation [9]. Based on a review of trenching experiments, Coomes and Grubb [10] proposed some general hypotheses, e.g., that light alone limits seedling growth in forests on moist, nutrient-rich soils, but that competition for belowground resources is more important on infertile soils and in drier regions. Early observations from the pine-dominated forest ecosystem of boreal Fennoscandia suggested that competition was fundamentally important, and many early researchers argued that belowground competition should be the most important factor in these systems [11-13]. Although some recent researchers agree with this notion [14], others have suggested that light is the most essential factor affecting the establishment and growth of pine seedlings [15-17]. However, studies on belowground competition are still under-represented in the literature, and empirical knowledge is consequently limited [10]; but, see, for example, Petritan et al. [5].

The regeneration of Scots pine (Pinus sylvestris L.) seedlings in the pine-dominated forest ecosystems of boreal Eurasia was already of interest 100 years ago; see, for example, [6,11,13,14,18-21]. Reduced regenerative growth of pine seedlings along edges or in the vicinity of retention trees is a commonly described pattern in boreal pine forest [11,20,22], and early research concluded that gaps within the forest should exceed a certain size in order to allow sufficient seedling establishment. Consequently, leaving seed-trees on relatively large clear-cuts has been the preferred method to foresee sufficient plant establishments. However, with the reconsideration of alternative forest practices, such as continuous cover forestry, the competitive mechanisms of importance for seedling establishment are in need of further examination. This is important not only in commercial forestry, but also in the restoration and conservation of remnant pine forests in, for example, Scotland [23,24]. 
In the present paper, we present results from two separate studies on seedling establishment in nutrient-poor pine forests typical of the northern boreal region of Fennoscandia. Our aim was to address the roles of aboveground competition for light and belowground competition for nutrients for pine seedling establishment beneath tree canopies. In the first study, we investigated the temporal patterns of pine seedling establishment following the stem-girdling of dominant trees performed 12 years earlier. Stem-girdling is a novel approach to disconnect, in the short-term (i.e., as long as the tree canopy remains intact), the influence of aboveground and belowground competition on seedling establishment. This method of interfering with belowground competition avoids a number of artifacts arising when more destructive techniques are used, such as soil trenching, which alters moisture and directly severs the structural integrity of roots and fungal hyphae. Earlier studies have shown that girdling instantaneously terminates the flux of photosynthates (sugars) from the tree canopy, via the phloem, to the roots and associated mycorrhizal fungi, while it initially allows the upward transport of water through the xylem [25]. Hence, during the two years following girdling, seedlings establishing beneath the canopy will be exposed to the same aboveground shading as before girdling (or on non-girdled control plots), while the belowground competition will be relaxed due to the lowering of nutrient uptake capacity by tree roots and their associated mycorrhizal fungi. This first study goes beyond the earlier initial studies on soil processes [25-27] to investigate if the relaxation of belowground competition with canopy trees can have long-term effects on pine seedling establishment and growth. In the second study, we explored the influence of being released from both above- and below-ground competition at forest edges on the pattern of pine seedling establishment. Previous studies from pine-dominated forests in other parts of the boreal region have demonstrated that across forest edges towards gaps, an approximately $10 \mathrm{~m}$-wide zone occurs, in which pine-seedling establishment and growth is poor, while beyond that zone, pine regeneration becomes denser $[11,20]$. In the present study, we contrast seedling establishment and growth across forest edges facing either north or south to test for any effects due to differences relating to the amount of solar radiation received by regenerating seedlings. We also conducted surveys on understory vegetation to explore correlations between pine seedling regeneration and the abundance of different understory plant species.

\section{Materials and Methods}

\subsection{The Study System}

The study was conducted in June-September in 2012 in a Scots pine forest at Åheden in the Vindeln Experimental Forest, Västerbotten, Sweden (6414' N, $19^{\circ} 46^{\prime}$ E, $175 \mathrm{~m}$ altitude). The mean annual temperature is $1.1^{\circ} \mathrm{C}$, and the average annual precipitation is $593 \mathrm{~mm}$, of which $\mathrm{ca} .40 \%$ falls as snow. The growing season (daily mean temperature $>5{ }^{\circ} \mathrm{C}$ ) starts in late May and ends in late September. The snow cover normally lasts from early November until early May. Climatic data corresponding to the study period can be found in Table 1. The understory vegetation consists mainly of lingonberry (Vaccinium vitis-idaea L.), heather (Calluna vulgaris L.), lichens (Cladonia spp.) and feather moss (Pleurozium schreberi). The soil is a weakly podzolized sediment of sandy silt with an organic mor-layer depth of $c a .2 \mathrm{~cm}$; the $C / N$ ratio of the mor is $40 \pm 5$ and the $\mathrm{pH}_{\mathrm{H}_{2} 0}$ is $4.0 \pm 0.1$ [27]. 
Similar forests are common in northern Fennoscandia $[6,11,18,19,21,28]$. In northern Sweden, this forest type covers $c a .1$ million hectares.

Table 1. Local climatic data during the growing season of the 13-year study period. The year denoted with an asterisk corresponds to the year of girdling.

\begin{tabular}{rccc}
\hline Year & Growing season (days) & Temperature sum & Precipitation (mm) \\
\hline $\mathbf{2 0 0 0 *}$ & 173 & 950 & 483 \\
$\mathbf{2 0 0 1}$ & 169 & 995 & 561 \\
$\mathbf{2 0 0 2}$ & 150 & 1228 & 216 \\
$\mathbf{2 0 0 3}$ & 139 & 1062 & 392 \\
$\mathbf{2 0 0 4}$ & 160 & 914 & 394 \\
$\mathbf{2 0 0 5}$ & 148 & 992 & 323 \\
$\mathbf{2 0 0 6}$ & 168 & 1206 & 307 \\
$\mathbf{2 0 0 7}$ & 144 & 922 & 312 \\
$\mathbf{2 0 0 8}$ & 170 & 844 & 341 \\
$\mathbf{2 0 0 9}$ & 151 & 988 & 382 \\
$\mathbf{2 0 1 0}$ & 151 & 1015 & 372 \\
$\mathbf{2 0 1 1}$ & 169 & 1225 & 404 \\
$\mathbf{2 0 1 2}$ & 146 & 889 & 361 \\
\hline
\end{tabular}

\subsection{Pine Seedling Establishment and Growth in a Tree Girdling Experiment}

To disentangle the influences of above- and below-ground competition on pine seedling establishment and growth beneath a tree canopy, we utilized a tree girdling experiment that had originally been set up in the year 2000. The forest stand covering $c a$. 10 ha is $c a .60$ years old and has naturally regenerated from seed trees. It consists of 1750 pines ha ${ }^{-1}$ with a dominant height of $17.6 \mathrm{~m}$, and the tree basal area is $30.8 \mathrm{~m}^{2}$ per ha ${ }^{-1}$. The girdling experiment consisted of six $30 \mathrm{~m} \times 30 \mathrm{~m}$ plots; in the treatment year, trees were girdled in early spring in three plots and in late autumn in the remaining three plots. Girdling was conducted by circumferential cutting of the bark at breast height (1.3 $\mathrm{m}$ above ground) of all trees. This terminates instantaneously the phloem flow of photosynthates from the tree canopy to the tree roots and their symbiotic ectomycorrhizal fungi $[25,29,30]$. As an immediate response, trees depleted the roots of their reserves of starch, after which the normal functioning of fine roots and mycorrhizal fungi ceased due to carbon starvation. However, upward xylem transport of water continued as the trees kept their needles for two growing seasons following the girdling [26]. Hence, these combined effects suggests that for the two years after girdling of dominant trees, emerging seedlings were released from competition belowground, but not from aboveground. Bhupinderpal-Singh et al. [26] reported that girdling did not cause any differences in soil temperature (measured in 2000 and 2001) and soil moisture (measured in 2000).

In 2012, we surveyed the temporal pattern of pine seedling establishment and growth beneath the trees following the girdling 12 years earlier. To get a representative sample of pine seedlings from each 900- $\mathrm{m}^{2}$ plot with girdled trees, we surveyed all large seedlings $(>50 \mathrm{~cm})$ in two $9 \mathrm{~m}^{2}$ sub-plots and all small seedlings $(\leq 50 \mathrm{~cm})$ in two corresponding plots of $1 \mathrm{~m}^{2}$ centered in the larger sub-plots. Corresponding plots in adjacent non-girdled forests were used as controls and were never more than $10 \mathrm{~m}$ away. We sampled the numbers, heights and ages of all pine seedlings. The age of large 
seedlings was estimated in the field by counting whorls and bud scars on the stem [31,32], whereas all small seedlings were uprooted and brought to the lab for age determination through a combination of counting whorls and bud scars on the stem and the cross-section technique described in Chojnacki [33]. The age of plants could then be used to determine their year of establishment and the mean annual height increment of each plant during their lifetime. As we did not study the possible difference between early- and late-season girdling, we standardized the relative establishment year of the plants accordingly.

\subsection{Pine Seedlings and Ground Vegetation in Forest Gaps in Relation to Edges}

We also surveyed pine seedlings establishment and growth along seven transects across north-facing forest edges and seven transects across south-facing forest edges at three different gaps in the Åheden pine forest. The gaps were created by clear-cutting ca. 20-25 years ago and were all in the vicinity of the girdled plots (0.2-1.2 km away), and the forest was similar to the forest surrounding the girdled plots. Gaps were also large enough $\left(9000 \mathrm{~m}^{2}-18,000 \mathrm{~m}^{2}\right)$ to encompass both north- and south-facing transects with a minimum of $10 \mathrm{~m}$ between the ends of the transects. By the south and north aspect of transects, our surveys were conducted at edges differing in the amount of solar radiation reaching seedlings. The cumulative photosynthetically active radiation along forest edges in these types of systems can be twice as high in edges facing south compared with edges facing north [17]. Transects extended from $10 \mathrm{~m}$ within the forest stands, across the forest edges, to $20 \mathrm{~m}$

beyond the edges into gaps. In each $1-\mathrm{m}^{2}$ section along transects, we counted the numbers and measured the heights of individual pine seedlings. We also surveyed the percentage cover of the dominating understory plant taxa, e.g., lichens (mainly Cladonia spp.), mosses (mainly P. schreberi), lingonberry ( $V$. vitis-idaea) and heather (C. vulgaris). Some grasses (Deschampsia flexuosa) and bilberry (Vaccinium myrtillus) occurred along one transect, but in such low abundances that they were excluded from further analyses.

\subsection{Statistical Analyses}

In the girdling experiment, the temporal patterns of pine seedling establishment, height and annual height increment were explored visually using standard statistical graphical tools. Nested ANOVA analyses were applied to test for significant differences in seedling numbers, mean heights and mean annual height increments in girdled and non-girdled plots. Nesting was set up hierarchically to account for both the two replicate samples in each plot and the two plots in each block.

For the analyses of pine seedlings (numbers and heights) along transects across forest edges, we used a linear mixed model with distance (from forest edge), aspect (north-facing and south-facing edges), the interaction between distance and aspect and ground vegetation species composition (as the result from a principal component analysis described below) as fixed factors. As several transects facing the same aspect could be in the same forest gap (seven transects facing each aspect were distributed on three gaps), transects were nested under gaps as a random factor in the model. As data derived from the transect may suffer from spatial autocorrelation, we conducted model selection based on the Akaike information criterion (AICc). In the model selection procedure, we selected model (spatial vs. unstructured), spatial covariance and spatial structure through best fit comparisons 
preferring low AICc scores over high [34]. To meet assumptions of heterogeneity, seedling numbers and heights were transformed before analyses by $\log (x+1)$ and $\log$, respectively.

A principal component analysis was done on the ground vegetation composition data to summarize the expressed variance in two principal components. The result of this analysis was included as fixed factors in the mixed model analysis of the seedling numbers and heights along the forest-to-gap transects.

Furthermore, for the ground vegetation data, we did a linear mixed model analysis similar to the one described above with the fixed factors distance (from forest edge), aspect (north-facing and south-facing edges) and the interaction between distance and aspect. Furthermore, for this model, transects were nested under gaps as a random factor in the model. To account for possible spatial autocorrelation, we applied AICc model selection as described above. To meet the assumptions of heterogeneity, we used the arcsin of the square-root of the ground vegetation data, which is the preferred transformation method for percentages or proportions [35].

All statistical analyses described above were conducted in JMP 11 [36].

\section{Results}

\subsection{Effect of Release from Belowground Competition through Tree Girdling}

The girdling treatment clearly increased both pine seedling establishment and growth. The total number of seedlings in girdled forests was substantially higher (seedling numbers corresponding to $\left.87,000 \pm 20,000 \mathrm{ha}^{-1}\right)$ than the number in adjacent non-girdled forest $\left(30,000 \pm 13,000 \mathrm{ha}^{-1}\right)$, and the ANOVA analyses show that this difference was significant $(p=0.0383)$. Similarly, both height and annual height increment was significantly higher in girdled plots compared to non-girdled plots ( $p<0.0001$ and $p=0.0007$, respectively). The mean height of seedlings in girdled plots was $68 \pm 8 \mathrm{~cm}$, while it was only $9 \pm 2 \mathrm{~cm}$ for plots in the trees that had not been girdled. The annual height increment of seedlings in girdled plots was $6.9 \pm 0.75 \mathrm{~cm} \cdot \mathrm{y}^{-1}$ compared to $2.7 \pm 2.35 \mathrm{~cm} \cdot \mathrm{y}^{-1}$ in plots where the trees had not been girdled.

The age reconstruction of pine seedlings established under girdled trees showed that only a low proportion $(\sim 3 \%)$ of the seedlings present in the plots had been established before the girdling event (Figure 1). Nearly $25 \%$ of the seedlings present in the plots had been established during the first and second year after girdling when girdled trees still maintained their needles (Figure 1). A major proportion of the seedlings, $47 \%$, had, however, been established during the third and fourth years following the girdling. This was the period when the needles of the girdled trees were shed, thus when the regeneration was also released from competition for light. By comparison, $97 \%$ of the pine seedlings currently present in non-girdled plots had been established at a time corresponding to more than four years after the girdling, during which time, the rate of regeneration did not differ much between girdled and non-girdled plots (two-sample $T$-test, $p=0.2028$ ).

In addition to the increased rate of seedling establishment, the girdling of canopy trees also seemed to stimulate the growth of seedlings already established. The few seedlings that had established before the girdling had a mean annual height increment of $c a .4 \mathrm{~cm} \cdot \mathrm{y}^{-1}$, whereas the seedlings established directly after girdling had a mean annual height increment of $c a .6 \mathrm{~cm} \cdot \mathrm{y}^{-1}$. The mean annual height 
increment of seedlings that had been established more than eight years after girdling was similar to, or even lower than, that in the seedlings that were established before the girdling (Figure 1).

Figure 1. Pine seedling establishments under girdled pine trees in relation to the time of girdling (bars, \% of total seedlings) and the seedlings' mean annual height increment during their lifetime $(\diamond)$ and present height $(\Delta)$. Values represent the current means of the seedlings established that particular year. Values above bars indicate the proportion (\%) of total establishments.

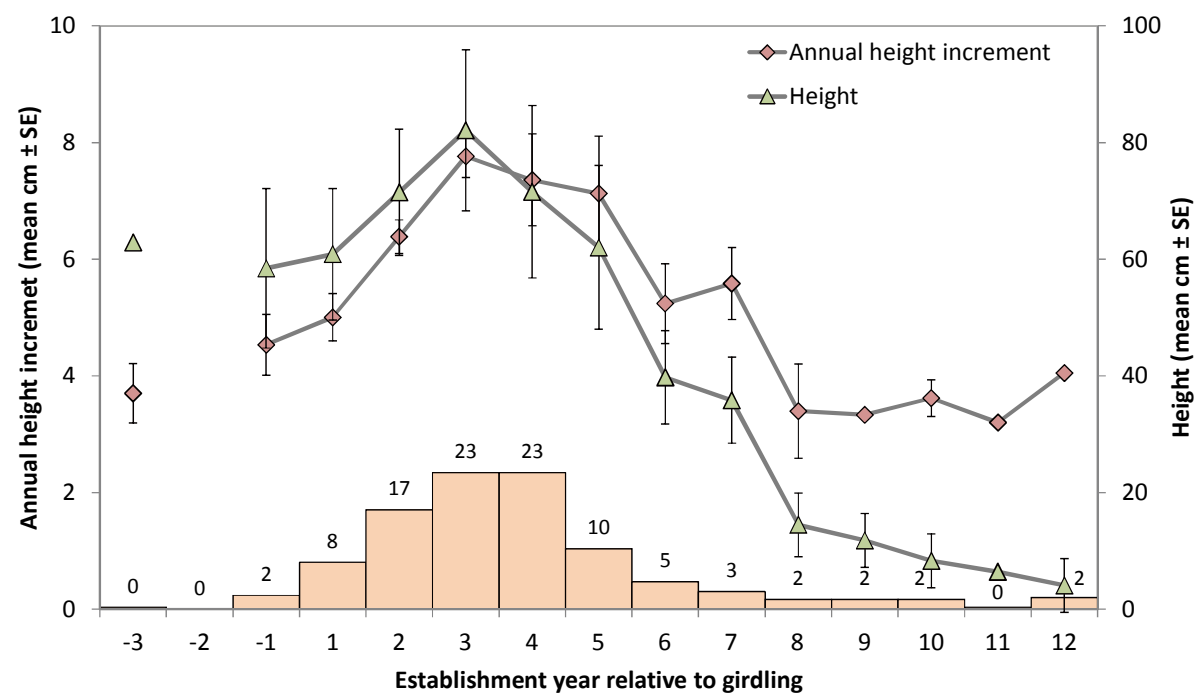

\subsection{Pine Seedling Establishment in Forest Gaps in Relation to Edges}

Pine seedling establishment and growth in forest gaps showed a clear response to both distance to forest edge and to its aspect. Both the numbers of seedlings and their mean height increased from within the forest stands towards the center of the forest gaps $(p=0.0062$ and $p<0.0001$, respectively; Figure 2, Table 2). However, although the number of pine seedlings increased already at the edge of the forest, their mean height remained low as far as 6-7 $\mathrm{m}$ into the gap, after which mean height increased (Figure 2). Moreover, the number of seedlings was higher at edges facing north than edges facing south ( $p=0.0205$; Table 2$)$, which predominantly is explained by the increased abundance of seedlings in the zone $10 \mathrm{~m}$ closest to the forest edge (Figure 2). The height distribution of seedlings was, however, similar for north- and south-facing edges $(p=0.3768$; Table 2$)$. Neither the number nor the height of seedlings was affected by interactions between distance from the edge and the aspect of the edge (Table 2).

The analyses of vegetation covariates showed that both Principal Components 1 and 2 correlated significantly with the number and heights of seedlings along the transects (Table 2). The significant correlation with Principal Component 1 ( $p<0.0001$, Table 2) suggests that the number of seedlings was positively correlated with the abundance of lichens or, alternatively, negatively correlated with the abundance of mosses. This relationship is shown by the contrasting loading of the two plant groups along Principal Component 1 (Figure 3). For seedling height, the lichen/moss correlation was reversed, so that seedlings were taller as mosses were more abundant $(p=0.0005$, Table 2). Principal Component 2, which is mainly described by the abundance of heather (Figure 3), was positively 
correlated with heights of seedlings ( $p<0.0077$, Table 2$)$. The ground vegetation also showed clear changes along the forest stand-to-forest gap transects (Figure 4, Table 3). For example, lichens and heather were significantly influenced by the distance to the forest edge, so that their abundances were higher out on clear-cuts compared to forested areas $(p<0.0001$ in both cases). For moss and lingonberry shrubs, the pattern was reversed, so that the abundances were higher in forested areas compared to gaps ( $p<0.0001$ in both cases).

Figure 2. Spatial patterns of the number of pine seedlings per $\mathrm{m}^{-2}$ and their mean height (cm) along 30-m transects going from inside the forest stand, out into forest gaps. On the $x$-axis, $0 \mathrm{~m}$ denotes the forest edge. The forest edges faced either north or south.
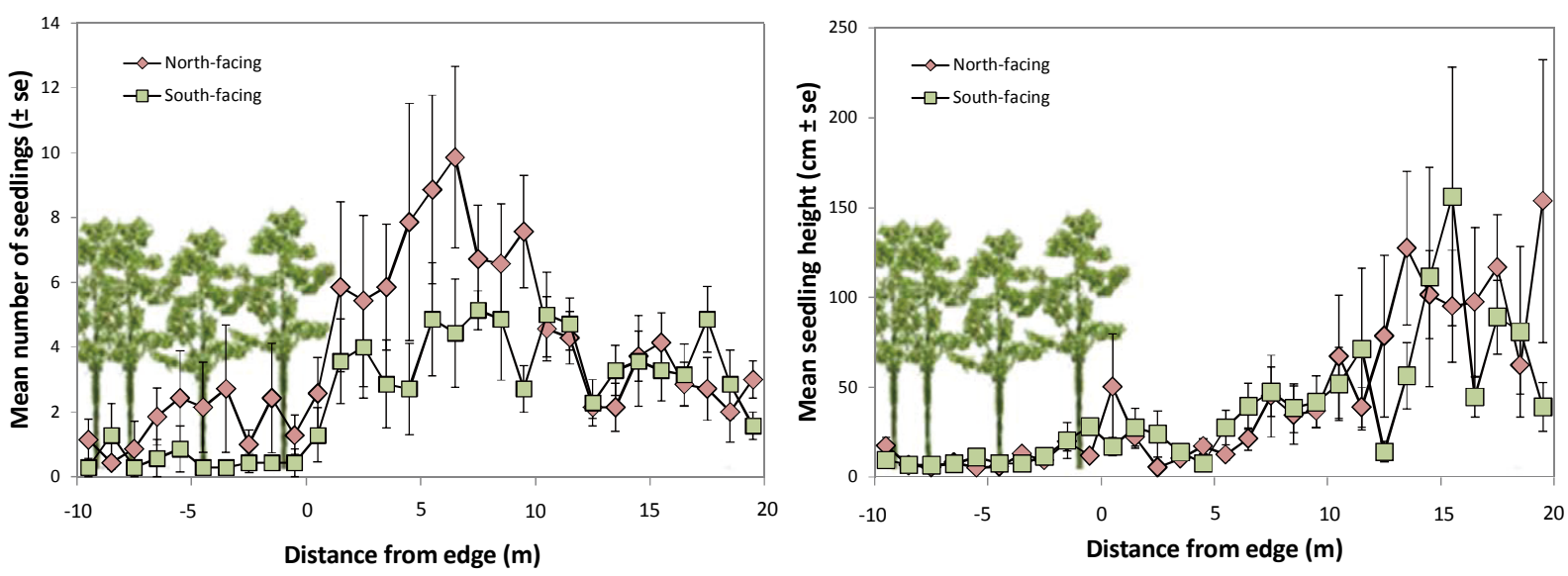

Table 2. The influence of the fixed effects distance from the forest edge and the facing of the edge towards north or south on the number and height of pine seedlings along transects across forest edges. Associations with principal components based on vegetation analyses are also shown. Principal Component 1 is primarily explained by the abundance of lichens (negative relation) and mosses (positive relation), and Principal Component 2 is primarily explained by the abundance of heather (positive relation).

\begin{tabular}{lccc}
\hline Source & Degrees of freedom & $\boldsymbol{F}$-value & $\boldsymbol{p}$-value \\
\hline Number of pine & & & \\
Facing & 1 & 6.3974 & 0.0205 \\
Distance & 1 & 7.8733 & 0.0062 \\
Facing $\times$ Distance & 1 & 0.2602 & 0.6119 \\
Principal Component 1 (-) & 1 & 16.6519 & $<0.0001$ \\
Principal Component 2 (+) & 1 & 0.0110 & 0.9165 \\
\hline Mean height & & & \\
Facing & 1 & 0.8088 & 0.3768 \\
Distance & 1 & 68.1455 & $<0.0001$ \\
Facing $\times$ Distance & 1 & 0.5661 & 0.4538 \\
Principal Component 1 (+) & 1 & 13.0360 & 0.0005 \\
Principal Component 2 (+) & 1 & 7.2251 & 0.0077 \\
\hline
\end{tabular}


Figure 3. The subdivision of vegetation covariates into the two main principal components subsequently used in mixed model analyses on pine seedling establishment and growth along transects going from inside the forest into forest gaps. Arrows give the strength and direction of the loading of the different taxa relative to the two main components. Component 1 explains $54.7 \%$ of the variation and is mainly related to the abundances of mosses (+ loading on PC1) and lichens (- loading on PC1). Component 2 explains 27.2\% of the variation and is mainly related to the abundance of heather (+ loading on PC2). The abundance of lingonberry shrubs loads on both PC1 (+) and PC2 (-).

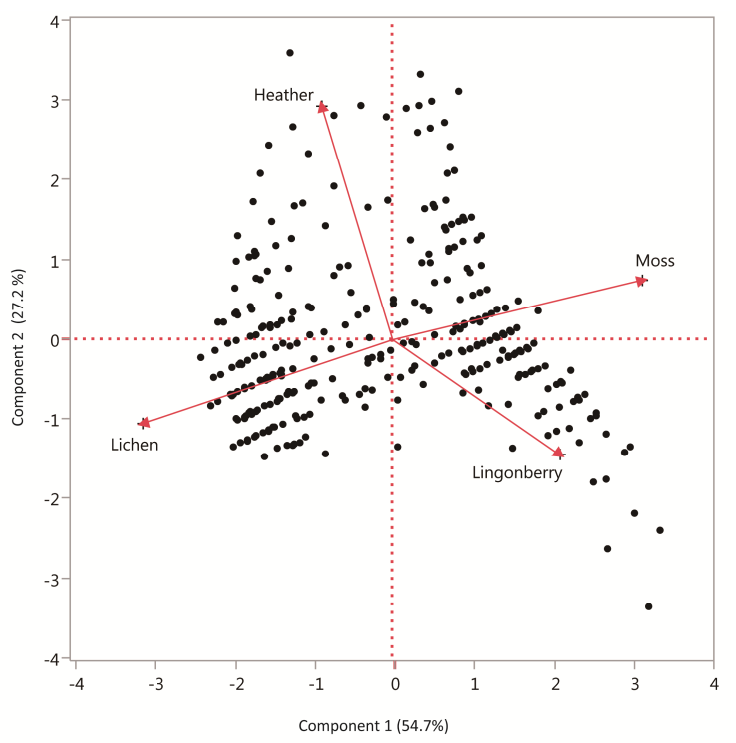

Table 3. The influence of the fixed effects distance from the edge and the aspect of the edge on the ground vegetation along edge transects.

\begin{tabular}{lccc}
\hline Source & Degrees of freedom & $\boldsymbol{F}$-value & $\boldsymbol{p}$-value \\
\hline Moss & & & \\
Facing & 1 & 0.3240 & 0.5772 \\
Distance & 1 & 25.3807 & $<0.0001$ \\
Facing $\times$ Distance & 1 & 0.0116 & 0.9151 \\
\hline Lichen & & & \\
Facing & 1 & 0.0402 & 0.844 \\
Distance & 1 & 27.4193 & $<0.0001$ \\
Facing $\times$ Distance & 1 & 0.8469 & 0.3643 \\
\hline Lingonberry & & & \\
Facing & 1 & 2.2270 & 0.1518 \\
Distance & 1 & 29.0796 & $<0.0001$ \\
Facing $\times$ Distance & 1 & 0.2140 & 0.6454 \\
\hline Heather & & & \\
Facing & 1 & 1.2409 & 0.2828 \\
Distance & 1 & 78.2066 & $<0.0001$ \\
Facing $\times$ Distance & 1 & 0.3274 & 0.5687 \\
\hline
\end{tabular}


Figure 4. Cover (\%) of dominant understory species along 30-m transects going from the closed forest into forest gaps. On the $x$-axis, $0 \mathrm{~m}$ denotes the forest edge. The forest edges faced either north or south.
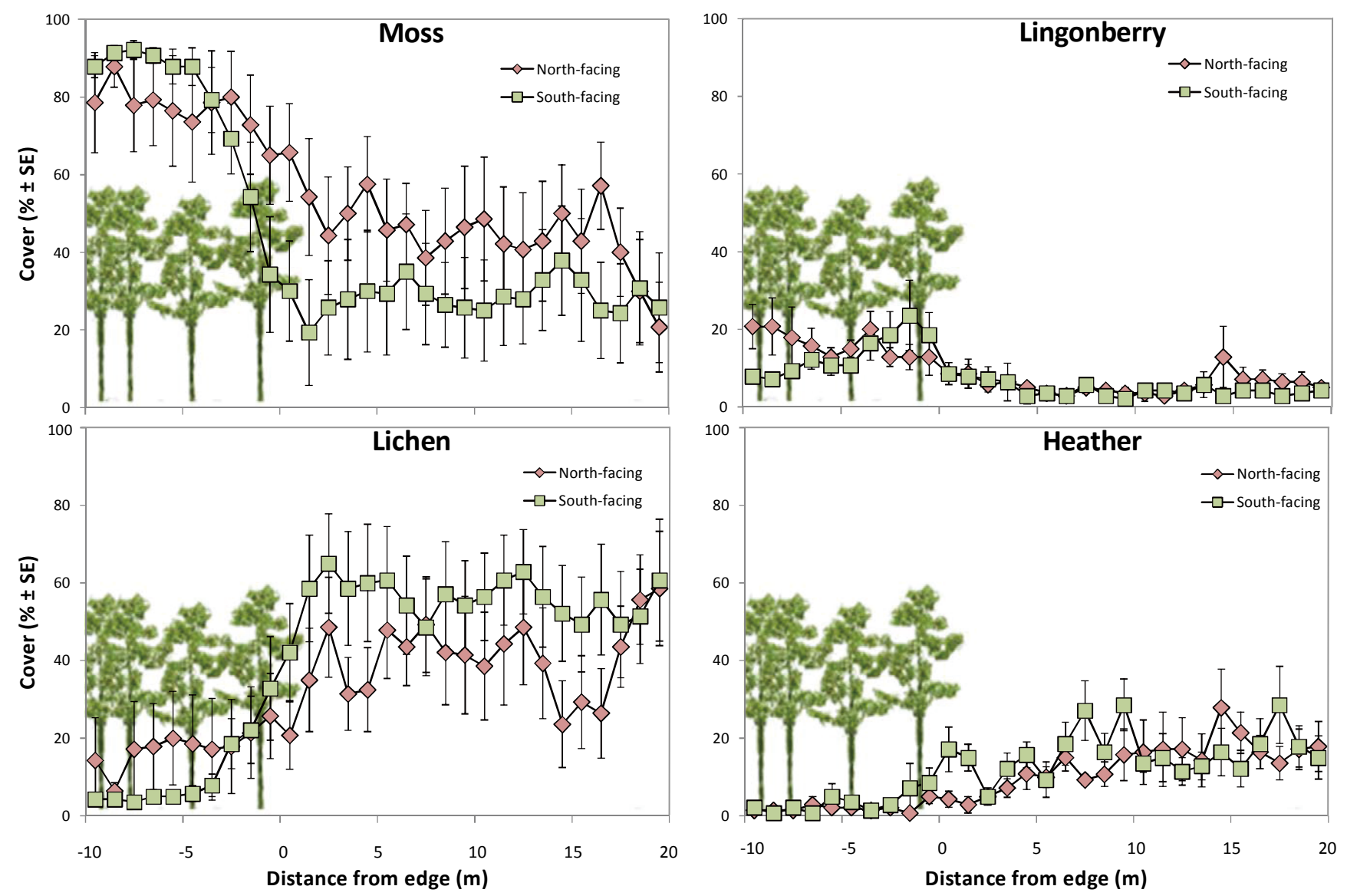

\section{Discussion}

Our results demonstrate that pine seedling establishment and growth in nutrient-poor boreal pine forests can be successful under a canopy of dominant trees, given that belowground competition with overstory trees is disrupted. Disrupting the belowground competition, while at the same time retaining the shading properties of the overstory canopy, resulted in the establishment of nearly 22,000 pine seedlings $\mathrm{ha}^{-1}$ during a two-year period, which is more than sufficient for normal stand development. The disruption of belowground competition may be attributed to competition for both water and nutrients and is likely to involve soil-associated microbes, such as ectomycorrhizal fungi. However, girdling initially does not affect the upward transport of water through the xylem [25]. The needles that remain in the canopy drive the water transport, and girdled trees should thus maintain their competitive ability for water as long as the canopy is intact. This is supported by Bhupinderpal-Singh et al. [26], who reported from the same study site that soil moisture during the first years after girdling did not differ between girdled and un-girdled plots. In contrast, the terminal effect of girdling on photosynthate transport from the tree canopy to the roots was instantaneous and pronounced. Previous reports from the same study site have shown that the termination of the downward photosynthate flow induced by stem-girdling of the dominant trees resulted in the soil microbial biomass being reduced by one-third within 1-3 months due to the loss of the extra-matrical mycelium of ectomycorrhizal 
fungi [27,30]. Thus, the establishment and growth of pine seedlings was clearly promoted by disrupting the interaction between the dominant trees and their ectomycorrhizal fungi, hence reducing the competitive ability of the dominant trees for available nutrients. Moreover, nitrogen locked in ectomycorrhizal mycelia, which were made available by decomposition, may have further promoted pine seedling development. The loss of ectomycorrhizal mycelial biomass during the three-month period following girdling was estimated to be equivalent to $c a .60 \mathrm{~kg} \cdot \mathrm{ha}^{-1}$ of carbon and approximately $6 \mathrm{~kg} \cdot \mathrm{ha}^{-1}$ of nitrogen [27]. An analysis of the isotopic composition of nitrogen in leaves of understory dwarf-shrubs, one year after girdling, suggested that nitrogen released from ectomycorrhizal mycelium became available for plant uptake at the time of pine seedling establishment after girdling [26]. However, the amount of soil nitrogen normally taken up by canopy trees in this type of forest is far higher [37] than the nitrogen potentially gained from the decomposition of mycelium. Hence, the main beneficial effect of tree girdling on seedling establishment at this stage is likely to be competitive release from the dominant trees and their associated microorganisms and not increased nitrogen availability.

In the third growing season following the girdling, the trees started to shed their needles [26], and their subsequent decomposition fertilized the site. Hence, while the aboveground competition for light was diminished beneath the tree canopy, nitrogen availability increased. Our estimations suggests that the trees shed approximately $6000 \mathrm{~kg}-7000 \mathrm{~kg}$ of needle biomass $\mathrm{ha}^{-1}$, which should contain approximately $50 \mathrm{~kg}-70 \mathrm{~kg}$ of nitrogen, of which about $50 \%$ may be released over the course of a few years. The relaxation of aboveground competition while the availability of nitrogen increased correlated with the establishment of the majority of pine seedlings ( $\left.c a .50,000 \mathrm{ha}^{-1}\right)$ that were still present on the plots 12 years after tree girdling.

We also studied pine seedling establishment and growth in forest gaps caused by clear-cutting confirming the conclusion from the girdling study that belowground competition is a main driver of pine seedling establishment and growth in boreal pine forests. Our result confirmed patterns of pine seedling establishment and growth previously observed in similar pine-dominated ecosystems in northern Finland nearly a century ago by Aaltonen [11] and later revisited by Kuuluvainen and Yllasjarvi [20]: that pine seedlings in the central areas of gaps grew better than seedlings closer to forest edges and that along the edges, there were 5 to $10 \mathrm{~m}$-wide zones in which there were about the same number of seedlings as there were further away from the edge, but which were growing relatively poorly. In an earlier study at our site, Göttlicher et al. [38] used two different methods, e.g., counting ectomycorrhizal sporocarps and ${ }^{15} \mathrm{~N}$ labeling, to estimate that the lateral spread of tree roots from tree trunks was about 4-5 m. Our observation of a 5 to $10 \mathrm{~m}$-wide zone with relatively poor pine seedling growth suggests that the distance influenced by belowground competition from a dominant tree may be slightly greater than the 4 to $5 \mathrm{~m}$ estimated by Göttlicher et al. [38]. However, the experimental study by Göttlicher et al. [38] was done within a few years following edge formation, whereas this study and the study by Aaltonen [11] were made along forest edges formed more than 10 years prior to the studies. It is plausible that dominant trees along forest edges expand their root systems into a gap over time to exploit any belowground resources being mobilized there.

In our comparison of north-facing and south-facing forest edges, we found that there were twice as many seedlings along edges with a northerly aspect than there were along edges facing south, while aspect had no effect on seedling height. This result contradicts those of previous studies in boreal 
forests, where a positive relation between seedling growth and incoming radiation has usually been indicated [15,17,31], although some negative or non-significant relationships have also been reported [12,39]. We agree with previous authors who point out that observational studies are of limited use when trying to evaluate the importance of radiation for seedling establishment and growth, since in these situations, radiation cannot be separated from belowground competitive interactions [17]. Nevertheless, a lack of clear positive effect on seedling growth in south-facing edges suggests that even quite high light levels are not enough to compensate for the depressing influence of canopy trees. Thus, the patterns of seedling establishment in the girdled forests should mainly be due to release from belowground competition and not over light. Moreover, in our study system, the larger number of seedlings found along north-facing forest edges may be due to more favorable abiotic conditions for seedling establishment, such as a higher supply of moisture and less extreme variations in temperature than along south-facing forest edges. Such differences in abiotic conditions are also indicated by the observed differences in the composition, dominance and diversity of other plant species growing on north- and south-facing forest edges. For example, moisture-demanding mosses were more abundant in gaps along north-facing edges, whereas drought-tolerant lichens dominated the bottom-layer vegetation in gaps along south-facing edges.

It has been suggested that interactions between tree seedlings and ground vegetation may influence seedling establishment [6,40]. Along the forest-to-gap transects, the ground vegetation underwent distinct compositional changes. Lichens and mosses replaced each other, with mosses dominating the bottom-layer vegetation in the forest, whereas lichens dominated in the gaps, particularly along south-facing forest edges. It has been suggested that pine seedling establishment in northern boreal pine forests is more successful on lichen-dominated microsites than on moss-dominated microsites [40]. In contrast, we found that the numbers of pine seedlings in gaps were significantly higher along north-facing edges, where mosses were more abundant, than along south-facing forest edges, where lichens were more abundant. Moreover, obviously the species composition of the understory vegetation reflects the environmental conditions of the site. As the same environmental conditions affecting ground vegetation also affect the tree seedlings, the mechanisms of cause and effect underlying the observed correlations between understory species composition and tree seedling establishment and growth are difficult to disentangle. It is, however, clear that the role of the understory vegetation for pine seedling establishment and growth is subordinate to the role of competition from dominant trees. Whereas shifts in understory species composition occurred sharply at the forest edge along the forest-to-gap transects, seedling growth was suppressed in gaps in a 5-10 m-wide zone along the edge.

Our results have clear implications for the practice of continuous cover forestry with single-tree selection cuttings. In such practices, the spacing between trees will determine the size of gaps created after harvest. Our data suggest that in this nutrient-poor ecosystem, the spacing between trees may need to be as large as $10 \mathrm{~m} \times 10 \mathrm{~m}$ in order to ensure a sufficient tree replacement, thus restricting the number of stems to approximately 100 trees $^{-1} \mathrm{~h}^{-}$. This is in agreement with empirical studies of the natural regeneration of pine on similar sites where the number of seed-trees per hectare often is recommended to be less than $100-150 \mathrm{ha}^{-1}$ to ensure that the seed-trees do not adversely affect the regeneration [39]. 


\section{Conclusions}

Forest management practices need to be based on sound knowledge of the ecological mechanisms that drive forest structure and function. Our study suggests that in nutrient-poor boreal pine forests, belowground competitive interactions can be a major driver of seedling establishment and growth. We show that the disruption of nutrient uptake by roots and ectomycorrhizal fungi of dominant trees instantly promotes seedling establishment and growth, even under a closed canopy. Further, our observations of pine seedling establishment and growth suggest that the inhibiting influence of belowground competition may affect pine seedling establishment up to $10 \mathrm{~m}$ away from dominant trees. We would like to point out that our study was undertaken within one forest area in northern Sweden and its scope of inference may be geographically limited. The patterns we describe have, however, been observed also in other regions of Fennoscandia with similar forest types [11,20,22], and they may apply in other regions with strongly nitrogen-limited forests, where theory predicts that belowground competition should be important [10]. Clearly, the generality of these results remains to be tested, and we encourage studies using the same approaches to test if belowground competition is of similar importance in other types of boreal forests that are less limited by nitrogen supply $[41,42]$.

\section{Acknowledgments}

We thank Anneli Lundmark for valuable assistance with fieldwork and Mona Högberg for constructive criticism on an earlier version of the manuscript. Financial support was provided by the TC4F (Trees and Crops for the Future) program and by the Future Forests program.

\section{Author Contributions}

Petter Axelsson: idea, sample design, field work, analyses and writing; Tomas Lundmark: idea, sample design and manuscript input; Peter Högberg: basic experimental setup and manuscript input; Annika Nordin: idea, sample design and writing.

\section{Conflicts of Interest}

The authors declare no conflict of interest.

\section{References}

1. Caplat, P.; Anand, M.; Bauch, C. Symmetric competition causes population oscillations in an individual-based model of forest dynamics. Ecol. Model. 2008, 211, 491-500.

2. Bartels, S.F.; Chen, H.Y.H. Interactions between overstorey and understorey vegetation along an overstorey compositional gradient. J. Veg. Sci. 2013, 24, 543-552.

3. Thorpe, A.S.; Aschehoug, E.T.; Atwater, D.Z.; Callaway, R.M. Interactions among plants and evolution. J. Ecol. 2011, 99, 729-740.

4. McCarthy, J. Gap dynamics of forest trees: A review with particular attention to boreal forests. Environ. Rev. 2001, 9, 1-59. 
5. Petritan, I.C.; von Lupke, B.; Petritan, A.M. Effects of root trenching of overstorey norway spruce (Picea abies) on growth and biomass of underplanted beech (Fagus sylvatica) and douglas fir (Pseudotsuga menziesii) saplings. Eur. J. For. Res. 2011, 130, 813-828.

6. Kuuluvainen, T.; Hokkanen, T.J.; Jarvinen, E.; Pukkala, T. Factors related to seedling growth in a boreal scots pine stand: A spatial-analysis of a vegetation-soil system. Can. J. For. Res. 1993, 23, 2101-2109.

7. Wagner, S.; Fischer, H.; Huth, F. Canopy effects on vegetation caused by harvesting and regeneration treatments. Eur. J. For. Res. 2011, 130, 17-40.

8. Chapin, F.S.; Bloom, A.J.; Field, C.B.; Waring, R.H. Plant-responces to multiple environmental-factors. Bioscience 1987, 37, 49-57.

9. Schwinning, S.; Weiner, J. Mechanisms determining the degree of size asymmetry in competition among plants. Oecologia 1998, 113, 447-455.

10. Coomes, D.A.; Grubb, P.J. Impacts of root competition in forests and woodlands: A theoretical framework and review of experiments. Ecol. Monogr. 2000, 70, 171-207.

11. Aaltonen, V.T. Über die natürliche verjungung der heidevälder im Finnischen lappland I. Commun. Inst. Forest. Finlandiae 1919, 1, 1-319. (In Finnish with German summary)

12. Björkman, E. On the influence of light on the height-growth of pine plants on pine heaths in Norrland. Medd. Stat. Skogsfors. Anst. 1945, 34, 497-542.

13. Romell, L.G.; Malmström, C. Henrik Hesselmans tallhedsförsök åren 1922-1942 the Ecology of Lichen-Pine Forest: Experiments (1922-1942) by the late dr Henrik Hesselman; Statens skogsförsöksanstalt: Stockholm, Sweden, 1945.

14. Strand, M.; Löfvenius, M.O.; Bergsten, U.; Lundmark, T.; Rosvall, O. Height growth of planted conifer seedlings in relation to solar radiation and position in scots pine shelterwood. For. Ecol. Manage. 2006, 224, 258-265.

15. de la Rosa, T.M.; Aphalo, P.J.; Lehto, T. Effects of far-red light on the growth, mycorrhizas and mineral nutrition of scots pine seedlings. Plant Soil 1998, 201, 17-25.

16. Pukkala, T.; Kuuluvainen, T.; Stenberg, P. Below-canopy distribution of photosynthetically active radiation and its relation to seedling growth in a boreal Pinus sylvestris stand-A simulation approach. Scand. J. For. Res. 1993, 8, 313-325.

17. De Chantal, M.; Leinonen, K.; Kuuluvainen, T.; Cescatti, A. Early response of Pinus sylvestris and Picea abies seedlings to an experimental canopy gap in a boreal spruce forest. For. Ecol. Manage. 2003, 176, 321-336.

18. Björkman, E.; Lundeberg, G. Studies on root competition in poor pine forests by supply of labeled nitrogen and phosphorus. Stud. For. Suec. 1971, 94, 1-16.

19. Hesselman, H. Studier över de norrländska tallhedarnas föryngringsvilllkor i. (studien uber die verjungungsbedingungen der norrlandischen kiefernheiden i.). Medd. Stat. Skogsfors. Anst. 1910, 7, 25-68.

20. Kuuluvainen, T.; Yllasjarvi, I. On the natural regeneration of dry heath forests in finnish lapland: A review of V. T. Aaltonen (1919). Scand. J. For. Res. 2011, 26, 34-44.

21. Rouvinen, S.; Kouki, J. Tree regeneration in artificial canopy gaps established for restoring natural structural variability in a scots pine stand. Silva Fennica 2011, 45, 1079-1091. 
22. Valkonen, S.; Ruuska, J.; Siipilehto, J. Effect of retained trees on the development of young scots pine stands in Southern Finland. For. Ecol. Manage. 2002, 166, 227-243.

23. Hancock, M.; Egan, S.; Summers, R.; Cowie, N.; Amphlett, A.; Rao, S.; Hamilton, A. The effect of experimental prescribed fire on the establishment of scots pine Pinus sylvestris seedlings on heather Calluna vulgaris moorland. For. Ecol. Manage. 2005, 212, 199-213.

24. Scott, D.; Welch, D.; Thurlow, M.; Elston, D.A. Regeneration of Pinus sylvestris in a natural pinewood in ne scotland following reduction in grazing by Cervus elaphus. For. Ecol. Manage. 2000, 130, 199-211.

25. Högberg, P.; Nordgren, A.; Buchmann, N.; Taylor, A.F.S.; Ekblad, A.; Högberg, M.N.; Nyberg, G.; Ottosson-Löfvenius, M.; Read, D.J. Large-scale forest girdling shows that current photosynthesis drives soil respiration. Nature 2001, 411, 789-792.

26. Bhupinderpal-Singh; Nordgren, A.; Löfvenius, M.O.; Högberg, M.N.; Mellander, P.E.; Högberg, P. Tree root and soil heterotrophic respiration as revealed by girdling of boreal scots pine forest: Extending observations beyond the first year. Plant Cell Environ. 2003, 26, 1287-1296.

27. Högberg, M.N.; Högberg, P. Extramatrical ectomycorrhizal mycelium contributes one-third of microbial biomass and produces, together with associated roots, half the dissolved organic carbon in a forest soil. New Phytol. 2002, 154, 791-795.

28. Hesselman, H. Studier över de norrländska tallhedarnas föryngringsvilllkor ii. (studien uber die verjungungsbedingungen der norrlandischen kiefernheiden ii.). Medd. Stat. Skogsfors. Anst. 1917, 13-14, 1221-1286.

29. Högberg, M.N.; Högberg, P.; Myrold, D.D. Is microbial community composition in boreal forest soils determined by $\mathrm{pH}, \mathrm{C}-$ to-N ratio, the trees, or all three? Oecologia 2007, 150, 590-601.

30. Yarwood, S.A.; Myrold, D.D.; Högberg, M.N. Termination of belowground C allocation by trees alters soil fungal and bacterial communities in a boreal forest. FEMS Microbiol. Ecol. 2009, 70, 151-162.

31. Gaudio, N.; Balandier, P.; Perret, S.; Ginisty, C. Growth of understorey scots pine (Pinus sylvestris L.) saplings in response to light in mixed temperate forest. Forestry 2011, 84, 187-195.

32. Brumelis, G.; Elferts, D.; Liepina, L.; Luce, I.; Tabors, G.; Tjarve, D. Age and spatial structure of natural Pinus sylvestris stands in latvia. Scand. J. For. Res. 2005, 20, 471-480.

33. Chojnacki, Y. About the method to determine accurately the age of saplings and the annual height growth of some forest tree species. Sylwan 1964, 1, 71-76.

34. Akaike, H. A new look at the statistical model identification. IEEE Trans. Automat. Contr. 1974, 19, 716-723.

35. Underwood, A.J. Experiments in Ecology; Cambridge University Press: Cambridge, UK, 1997.

36. SAS. Discovering JMP; SAS Institute Inc.: Cary, NC, USA, 2010.

37. Melin, J.; Nommik, H.; Lohm, U.; Flower-Ellis, J. Fertilizer nitrogen budgets in a scots pine ecosytem attained by using root-isolated plots an N-15 tracer technique. Plant Soil 1983, 74, 249-263. 
38. Göttlicher, S.G.; Taylor, A.F.S.; Grip, H.; Betson, N.R.; Valinger, E.; Högberg, M.N.; Högberg, P. The lateral spread of tree root systems in boreal forests: Estimates based on N-15 uptake and distribution of sporocarps of ectomycorrhizal fungi. For. Ecol. Manage. 2008, 255, $75-81$.

39. Erefur, C.; Bergsten, U.; de Chantal, M. Establishment of direct seeded seedlings of norway spruce and scots pine: Effects of stand conditions, orientation and distance with respect to shelter tree, and fertilisation. For. Ecol. Manage. 2008, 255, 1186-1195.

40. Steijlen, I.; Nilsson, M.C.; Zackrisson, O. Seed regeneration of scots pine in boreal forest stands dominated by lichens and feather moss. Can. J. For. Res. 1995, 25, 713-723.

41. Jarvis, P.; Linder, S. Botany: Constraints to growth of boreal forests. Nature 2000, 405, 904-905.

42. Tamm, C.O. Nitrogen in Terrestrial Ecosystems. Questions of Productivity, Vegetational Changes, and Ecosystem Stability; Springer Verlag: Berlin, Germany, 1991.

(C) 2014 by the authors; licensee MDPI, Basel, Switzerland. This article is an open access article distributed under the terms and conditions of the Creative Commons Attribution license (http://creativecommons.org/licenses/by/3.0/). 